\title{
LA VIVIENDA DE EMPORION: UN EJEMPLO DE UNA SOCIEDAD ECLÉCTICA EN EL MEDITERRÁNEO OCCIDENTAL EN ÉPOCA CLÁSICA
}

\author{
THE HOME OF EMPORION: A CLEAR EXAMPLE OF A ECLECTIC SOCIETY IN THE WESTERN \\ MEDITERRANEAN IN CLASSICAL TIMES
}

ADA CORTÉS VICENTE

Grupo de Investigación Universitat Autònoma de Barcelona Institut Català d'Arqueologia Clàssica

La Ampurias romana es el producto de una larga evolución histórica y de múltiples influencias culturales. A lo largo de los siglos, el municipio vislumbró una gran variedad de tradiciones arquitectónicas (griegas, íberas, púnicas e itálicas) transmitidas a través de su urbanismo. Ésta es su gran riqueza y particularidad, que también se muestra en su arquitectura doméstica.

Para analizar la vivienda y el desarrollo de la arquitectura se debe diferenciar claramente entre la «Neapolis» (Emporion) y la ciudad romana (Emporiae) (Fig. 1). Los dos núcleos responden a trayectorias diferentes, el asentamiento romano es una ciudad construida ex novo con una población de colonos itálicos, mientras que la «Neapolis» tiene un origen griego con una evolución larga y muy compleja.

Es en la «Neapolis» donde más se acentúa esta particularidad, que es perceptible aún bajo la fuerte reorganización urbanística llevada a cabo durante la segunda mitad del siglo II a.C. (Fig. 2). Gracias a 100 años de excavaciones arqueológicas y principalmente después de las últimas intervenciones estratigráficas al yacimiento, se puede atestiguar esta transformación urbanística en el interior de las murallas de la antigua colonia focea a partir del s. II a.C. (Santos, 2008, 6772). Las casas que se encuentran durante este período histórico en la «Neapolis», a excepción de las casas de

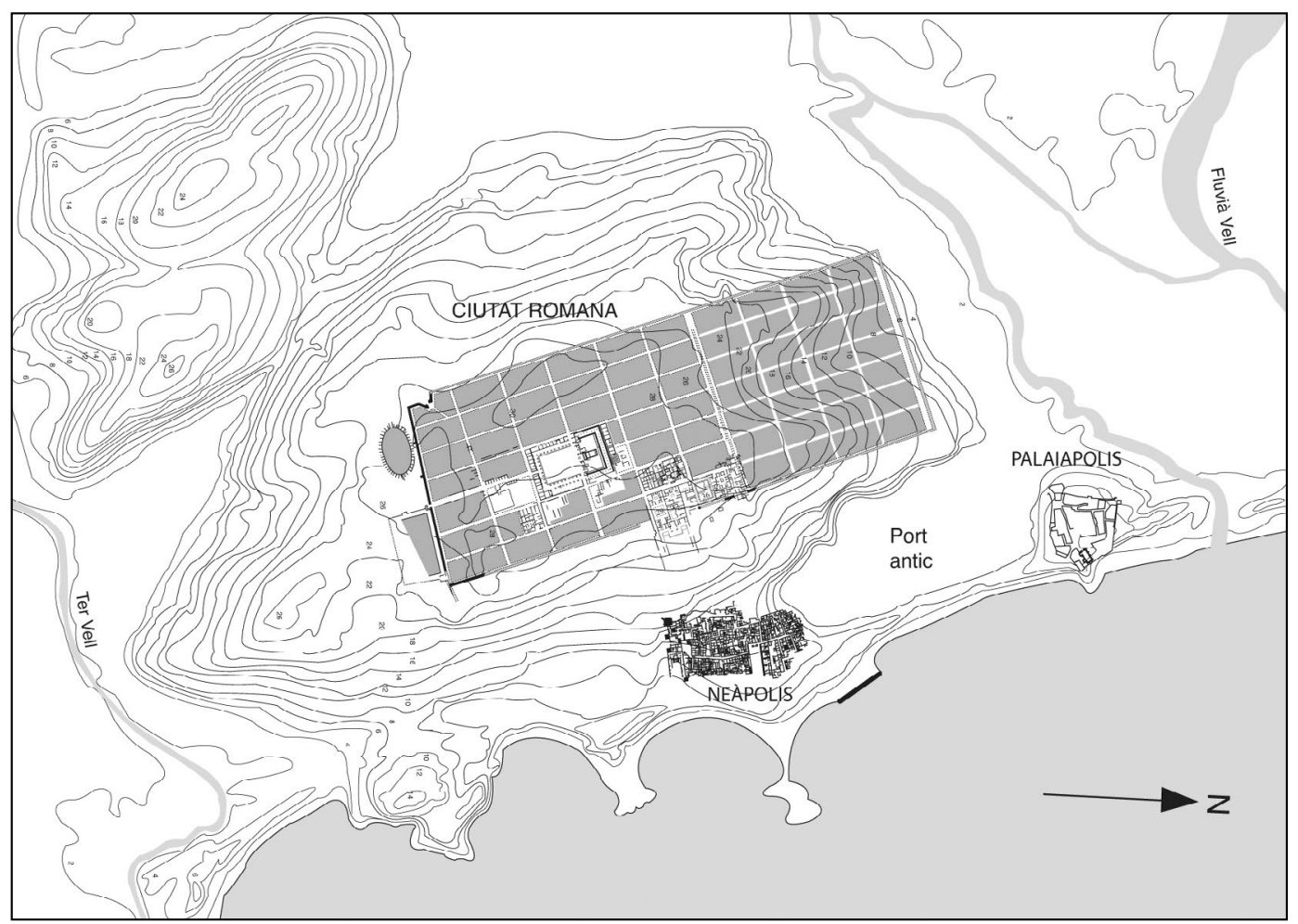

Figura 1: Planta general del yacimiento de Ampurias. Situación de la ciudad romana, del núcleo griego («Neapolis») y del asentamiento originario («Palaiapolis») (Aquilué, 2006, 18). 


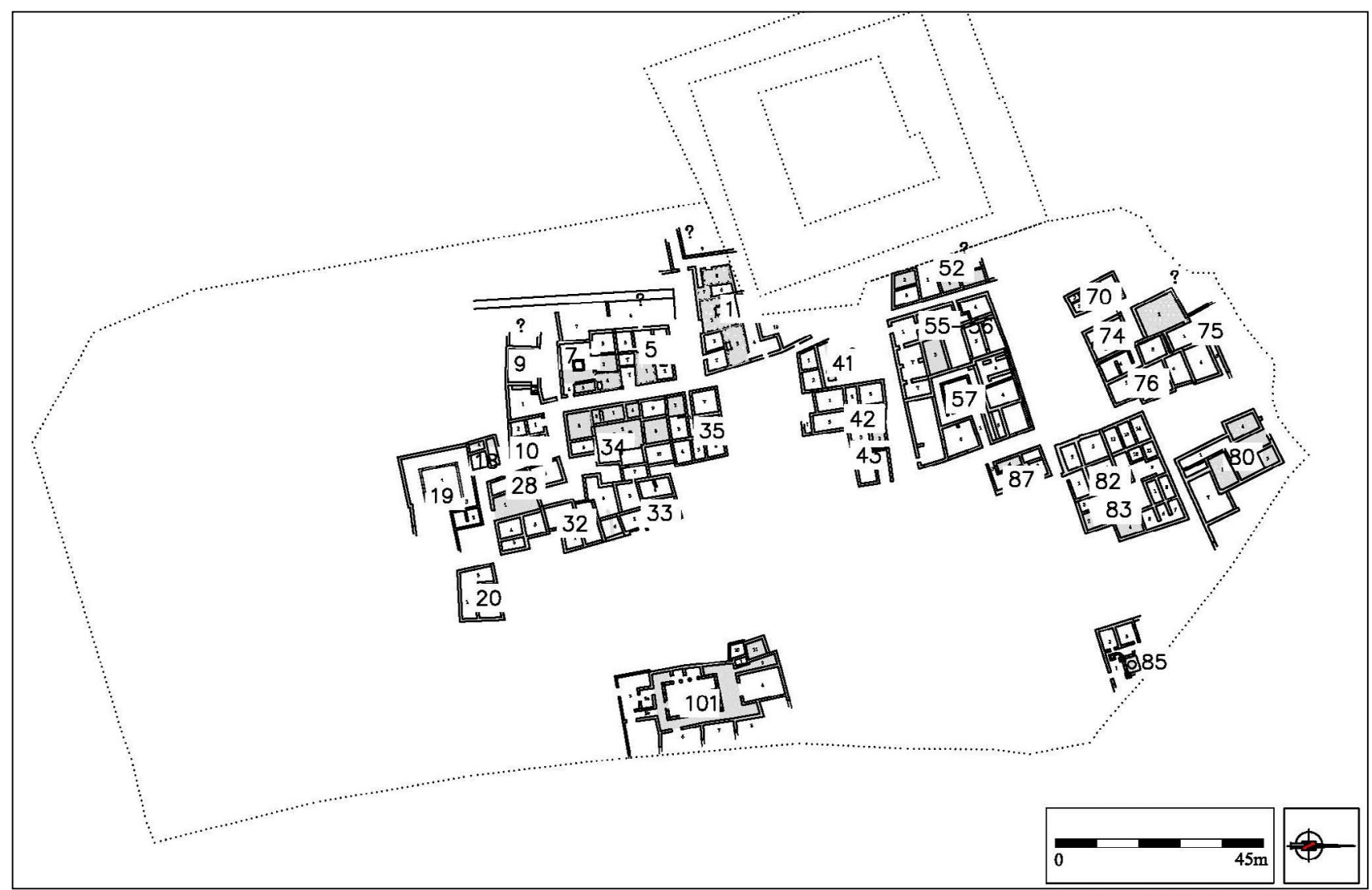

Figura 2: Situación de las diferentes casas de la «Neapolis» con la numeración del catálogo urbanístico efectuado por R. Mar y J. Ruiz de Arbulo (1993). (Cortés, 2014, 28).

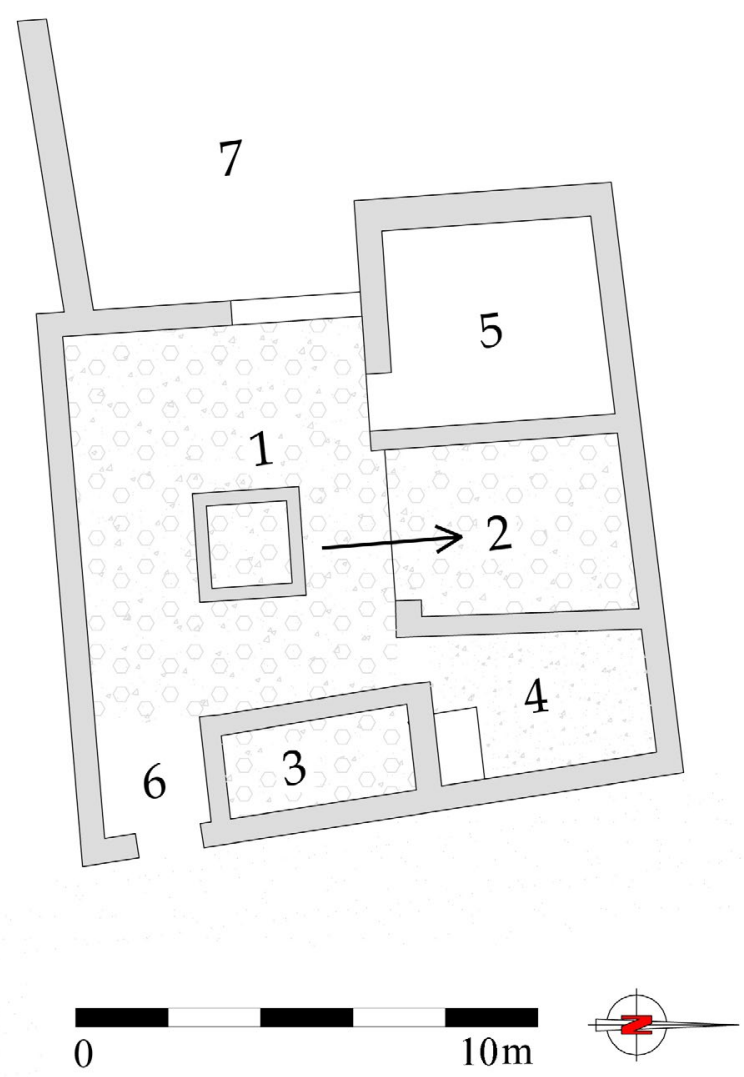

Figura 3: Planta de la casa 7 de la «Neapolis» (base planimétrica: Aquilué et alii, 1983, 132).

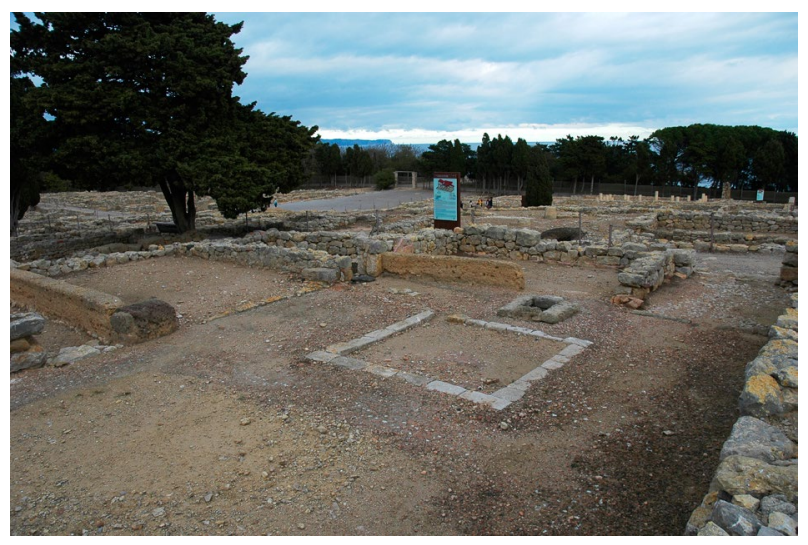

Figura 4: Vista general de la casa 7 en la que se puede apreciar el atrio toscano y el tablinum abierto a este.

peristilo, no corresponden generalmente a las clásicas denominaciones tipológicas griegas (prostas, pastas, herdnaum, peristilo). Aunque Balil $(1972,43)$ intuyó una casa de prostas en la estructura de la casa 7 con similitudes a las casas de Olinto y Priene, el conocimiento actual de la vivienda permite identificarla como una casa de atrio (Figs. 3 y 4). Aún así, estas casas sí muestran elementos que podrían identificarse con un origen griego. La introducción de nuevos esquemas itálicos en el urbanismo emporitano no llegó a frustrar la supervivencia del componente griego ni el de otras influencias, como la ibérica e incluso la 
púnica. Además, también se debe tener en cuenta que esta riqueza de elementos se desarrolla en un espacio de dimensiones limitadas y de una larga trayectoria urbanística.

\section{SUSTRATO CULTURAL DE LAS TIPOLOGÍAS DE LAS CASAS DE EMPORION}

Las casas de Emporion que se han podido documentar y estudiar en profundidad son las viviendas levantadas durante la última fase urbanística de la ciudad. Estas estructuras arquitectónicas son casas existentes en el último momento de utilización de la ciudad. Son edificios con una trayectoria histórica compleja, pero que se engloban dentro de una misma fase constructiva. Se debe recordar que la excavación de casi la totalidad de la «Neapolis» se hizo a principios del s. XX, con muy pocos datos estratigráficos y sin una separación cronológica exacta de cada unidad doméstica. Este último momento urbanístico, cuando la «Palaiapolis», la «Neapolis» y la ciudad romana actúan como una misma área urbana, se sitúa hacia al cambio de era y el s. I d.C., pero con importantes pervivencias de época republicana que condicionan el urbanismo de esta fase (Aquilué et alii, 1983, 131).

Las unidades domésticas catalogadas (Cortés, 2009, 37-107; Cortés, 2014, 26-77) corresponden a plantas de viviendas simples sin espacio central o distribuidor, casas desarrolladas alrededor de un local comercial o artesanal y casas sencillas o más complejas con una área central de distribución (éstas con un porcentaje de ejemplos más elevado). El espacio central, neurálgico y de distribución de estas casas de la ciudad griega, se puede encontrar con más o menos relevancia, cubierto o descubierto y ocupando un espacio más amplio que el resto de las estancias. En algunos ejemplos, concretamente en dos casas, el espacio de distribución simplemente se establece como un pasillo, una zona de paso entre distintos ámbitos. Finalmente, en este núcleo urbano también se han documentado las tipologías de casa de atrio, casa de peristilo o patio porticado ${ }^{1} \mathrm{y}$ un único ejemplo de casa de atrio y peristilo (Fig. 5).

La mayoría de las paredes de las casas están levantadas con la misma técnica, zócalos de aparejo irregular en seco y superestructura de tapial. Hay excepciones, como algunas de las paredes de la casa 7, construidas solo con tapial. También se detectan muros más grandes y regulares que refuerzan zonas concretas de la estructura doméstica, pero lo más destacado respecto a la técnica común son las paredes con mortero de cal. Antes de la llegada de los romanos, el uso del mortero de cal en la «Neapolis» era limitado, principalmente se destinaba a las obras hidráulicas. El mortero junto a la utilización de un aparejo pequeño es una técnica

1. Para ver las diferencias y matices entre la casa de peristilo y de patio porticado ver Cortés, 2011, 18; 2014, 311-315. constructiva datable en el s. I d.C. Es el caso de algunas paredes de la casa $5 .^{2}$ En cuanto a los suelos de las casas, la gran mayoría de ellas estaban provistas de superficies de tierra apisonada con alguna alternancia de pavimentos de opus signinum, muchos de ellos con decoración de teselas y fragmentos de marmorea. La singularidad la determinan algunos pavimentos de opus tessellatum exhumados en las casas 52 y 19 , y un opus spicatum de la casa 82 . Este último pavimento ha sido datado en época romana por la comparación con uno de los pavimentos del recinto termal de la fase bajorepublicana y augustal de la insula 30 de la ciudad romana (Aquilué et alii, 2006, 39), descubierto en una excavación estratigráfica.

Como se adelantaba en el inicio del artículo, es a través de estas estructuras que es posible distinguir en mayor o menor grado las diferentes influencias y sincretización que recibió la vivienda de la ciudad griega de Emporion. La exposición que se efectuará a continuación sobre esta diversidad cultural es una reflexión desde el punto de vista de las tipologías y las plantas que ofrece esta ciudad. El estudio y comparativa de estas tipologías es el elemento más efectivo para realizar esta observación, ya que es uno de los aspectos de análisis de la «Neapolis» con ventaja en comparación con otros yacimientos urbanos. En la «Neapolis» se puede observar la planta completa de las casas y tener la seguridad de que se analiza la casi totalidad de las viviendas que existieron en ese periodo histórico, al tener excavada una gran parte de la ciudad. Por desgracia, el estado de muchas de las casas y las condiciones de excavación, no permiten hacer un análisis muy profundo de su técnica constructiva y la cronología exacta de sus fases edilicias. Aunque sí permite apreciar algunos elementos constructivos que se introdujeron a partir de la fundación de la ciudad romana, como la utilización más frecuente del mortero de cal o la aparición de algunos opus en los pavimentos. Estos elementos ayudan a concretar mejor esta influencia itálica en la vivienda, pero es el estudio de la estructura de las casas y el desarrollo y disposición de sus plantas como mejor ser puede analizar y comparar la vivienda emporitana.

El contacto con los romanos a partir del siglo II a.C. proporcionó a esta ciudad el flujo de influencias culturales y arquitectónicas itálicas que se observa con claridad en los templos con paralelos arquitectónicos en la ciudad de Fregellae (Sanmartí et alii, 1990, 141142) o en el esquema itálico utilizado en las «termas de la basílica» (Palauí y Vivó, 1993, 109-111). Como

2. Técnica constatada estratigráficamente en la ciudad romana, como en las termas de la insula $30 \mathrm{y}$ el foro (Aquilué et alii, 1984, 78). Pero se debe tener en cuenta que solo una parte de las estructuras de las casas están construidas con paredes con mortero de cal, nunca todo el conjunto. Así pues, estos muros están reflejando movimientos arquitectónicos, reestructuraciones y restauraciones de las casas ya existentes, muchas de ellas de segunda mitad del s. II a. C. 


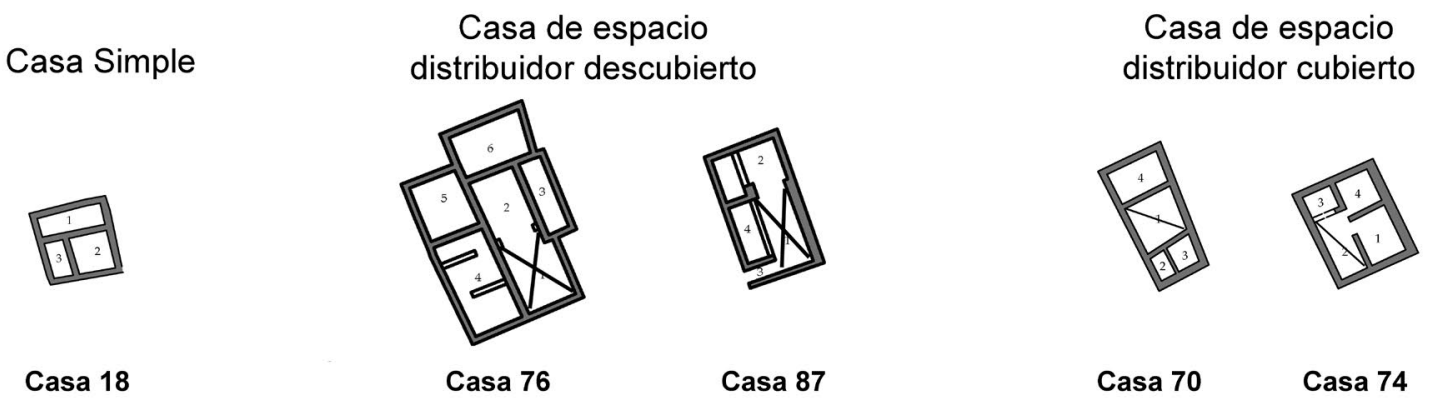

Local con dependencias

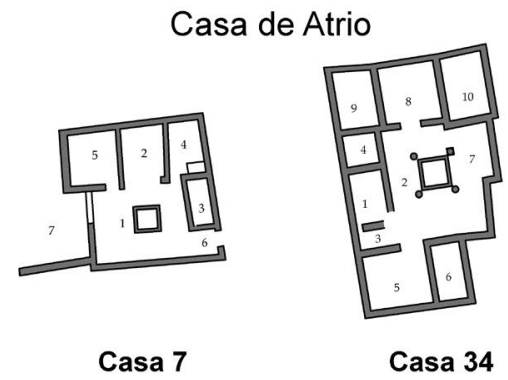

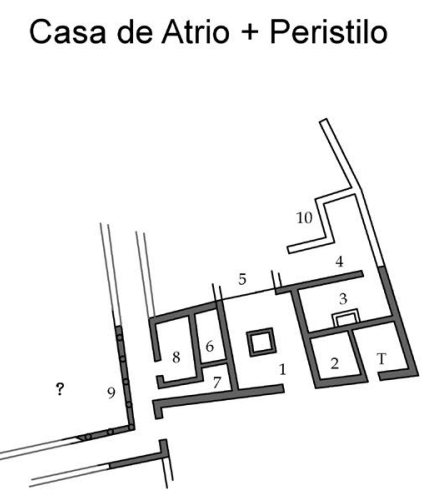

Casa 1

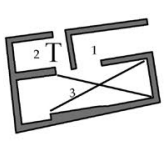

Casa 43

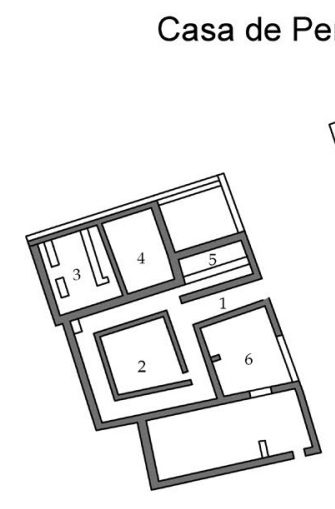

Casa 57

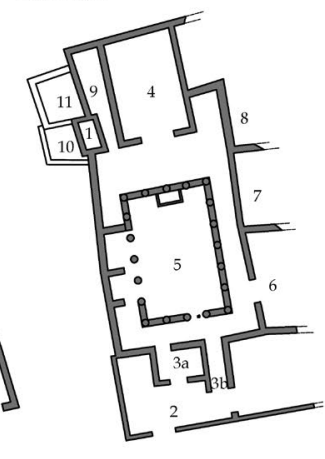

Casa 101
Casa de patio porticado

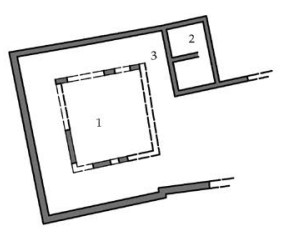

Casa 19

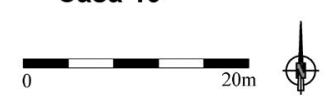

Figura 5: Ejemplos de las tipologías de las casas de la «Neapolis». El espacio distribuidor descubierto o patio marcado con una X, el espacio distribuidor cubierto con una $\backslash$ y el local comercial o taberna con una $\mathrm{T}$.

se ha comentado, evidentemente este traspaso de esquemas itálicos fue mucho mayor con la creación de la ciudad romana en el montículo situado al oeste del núcleo griego (Cortés y Guitart, 2010, 34-38). Uno de los elementos más emblemáticos es la introducción de la casa de atrio, que en la «Neapolis» se traduce de un modo peculiar. La casa de atrio no sólo se adapta al espacio que ofrece la dinámica urbanística sino que también a una cierta concepción griega de la vivienda. El caso más evidente es el de la casa 34 que estructuralmente se podría definir como una casa de peristilo pero con la diferencia de disponer de un atrio en lugar de un peristilo (Figs. 6 y 7).

Esta casa se desarrolla alrededor de un atrio tetrástilo, sin ejes de simetría y con una entrada lateral. Uno de los paralelos más cercanos de esta disposición arquitectónica se encuentra en la Grecia de época romana, en la ciudad de Patrás (Fig. 8). A pesar de que morfológicamente el espacio descubierto de esta casa se identifica como un atrio tetrástilo, su situación de centralidad (el resto de estancias se ubican a su alrededor, sin simetría ni axialidad) hace que el espacio actúe como un peristilo (Bonini, 2006, 56-59). Bonini define este fenómeno, documentado también en otras ciudades de la Grecia de época romana, como una tipología híbrida de patio tetrástilo. En el caso de la casa 34, se debería optar también por esta clasificación. En Paestum, ciudad de origen griego y con una posterior romanización o influencia romana, como en Emporion y Patrás, también se puede observar otro ejemplo similar, un patio de cuatro columnas con la misma problemática que se podría catalogar igual que las anteriores. Este patio se localiza en la casa C de la insula $\mathrm{In}(\mathrm{n}-2)$ (Lemaire et alii, 2000, 160) (Fig. 9).

Balil (1972, 43-46) reflexionaba sobre la particularidad del tipo de casas que se descubrían en la 


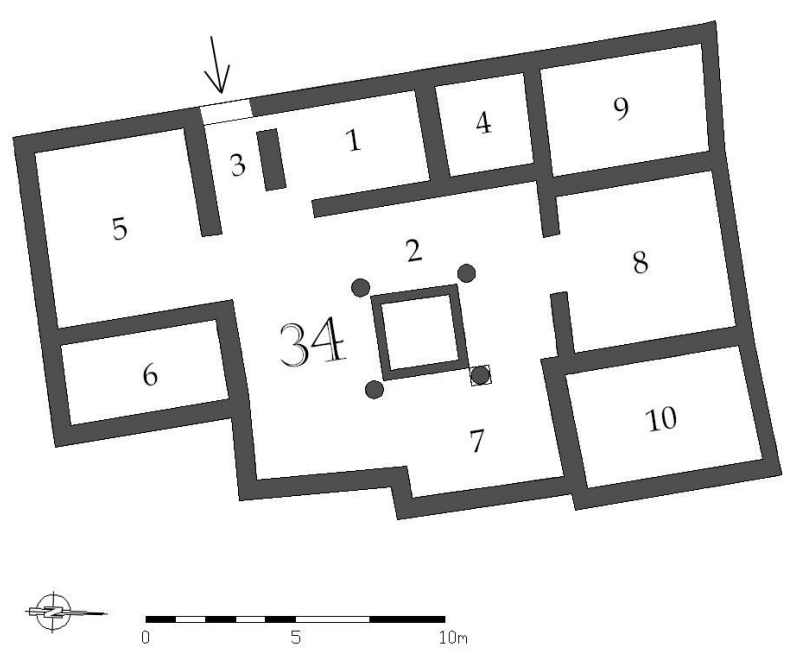

Figura 6: Planta de la casa 34 de la «Neapolis» (base planimétrica: Aquilué et alii, 1983, 132).

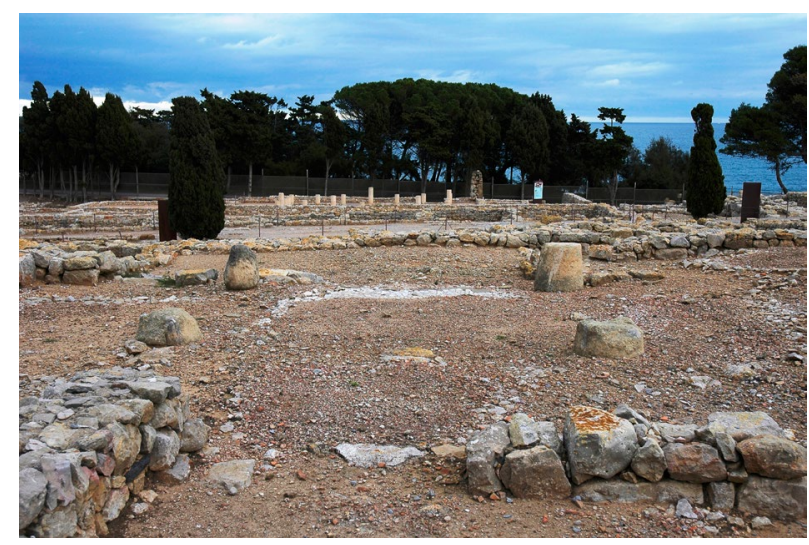

Figura 7: Zona neurálgica de la casa 34.

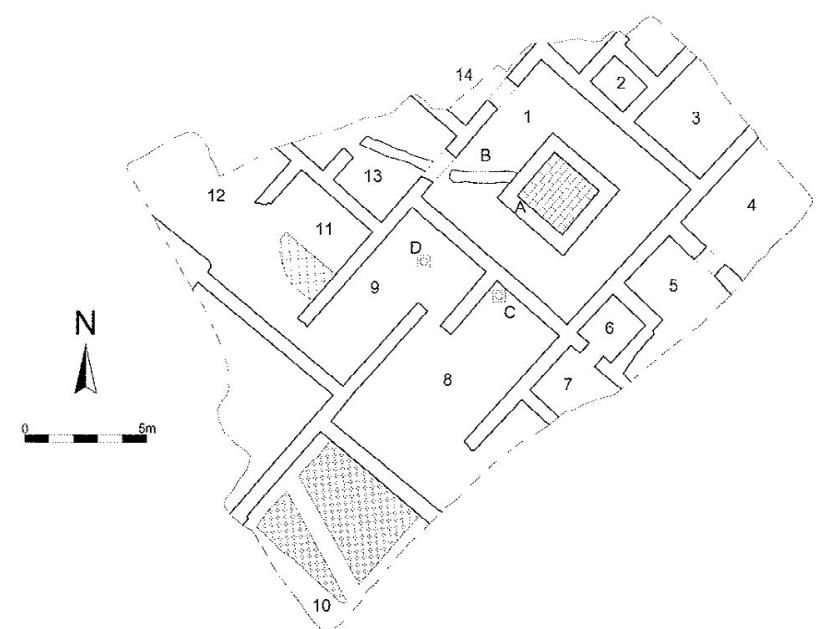

Figura 8: Planta de la casa de Patrás (Bonini, 2006, 447).

«Neapolis» y llegó a la conclusión de que no se podía hablar de casas de atrio, idea recogida más tarde por otros autores como Zaccaria $(1995,380)$. Actualmente sí que se han documentado casas de atrio. Si bien la

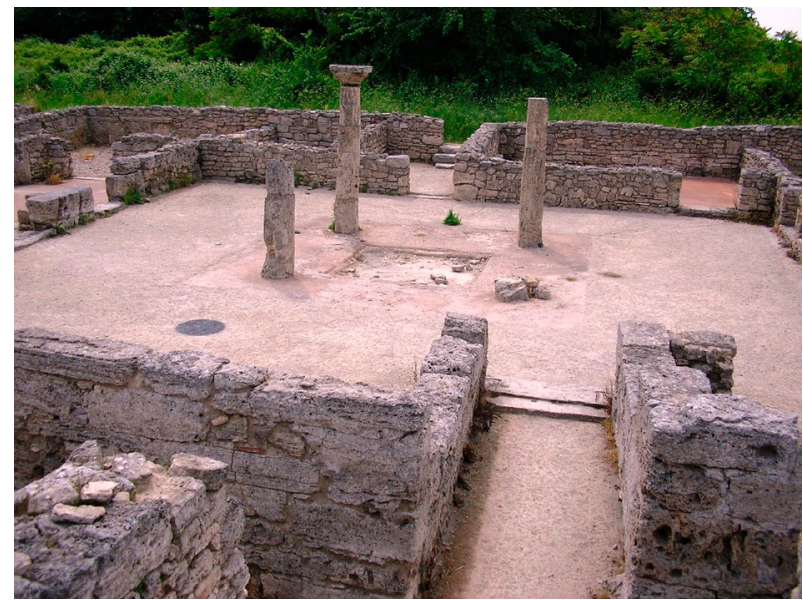

Figura 9: Vista general de la casa $C$ de la insula In (n-2) de Paestum.

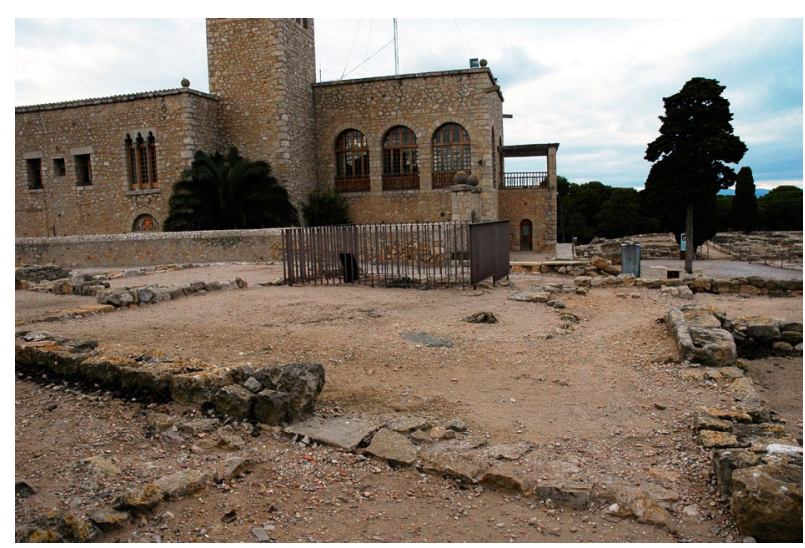

Figura 10: Vista general del sector del atrio de la casa 1 de la «Neapolis».
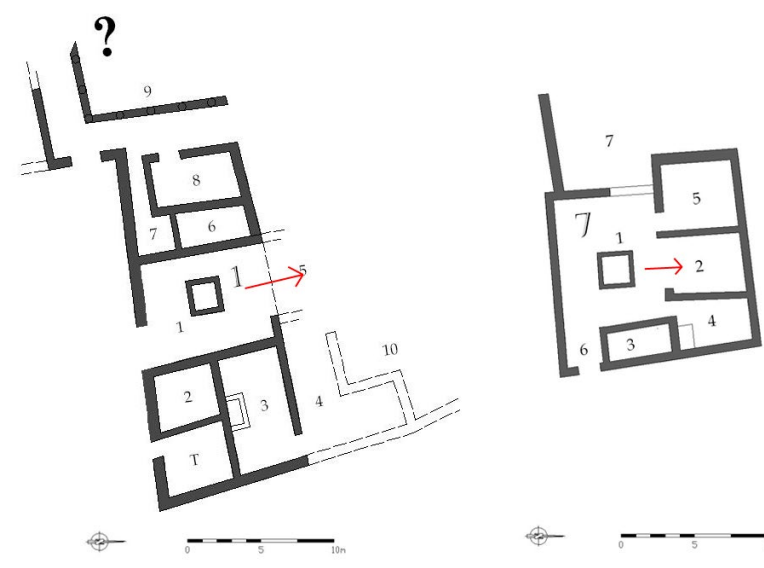

Figura 11: Plantas de las casas 1 y 7 de la «Neapolis» con el eje de simetría señalado.

casa 34 debe entenderse como una casa de patio tetrástilo, no sucede lo mismo con las casas 1 y 7 (Figs. 3,4 y 10). En estos dos atrios, a pesar de no presentar el esquema axial típico fauces / atrium / tablinum, sí 


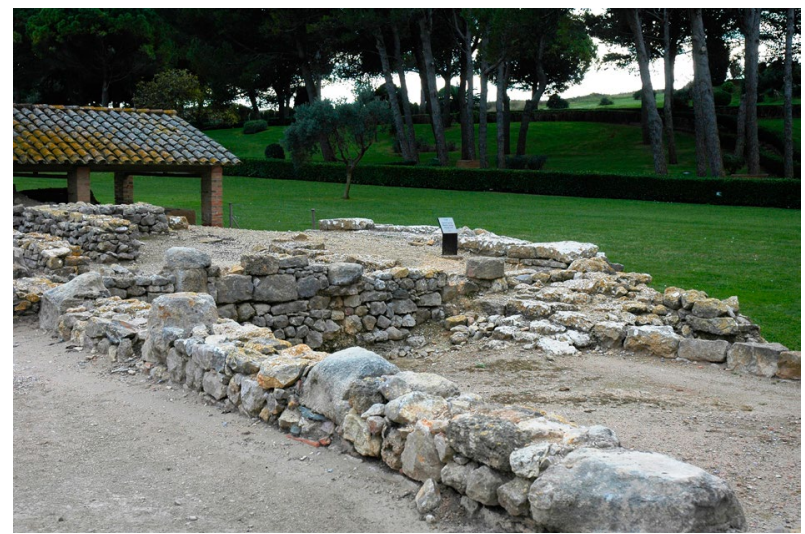

Figura 12: Restos del peristilo de la casa 1 de la «Neapolis». se puede observar la búsqueda de una axialiadad, principalmente entre el impluvium y el atrio respecto del tablinum (Fig. 11). En estos dos casos la adecuación del esquema itálico correspondería más bien a una adaptación del espacio urbanístico. Cabe recordar que este espacio es más reducido que en la 'nueva' ciudad romana y que además, se encuentran los restos de edificaciones anteriores. La introducción de dos posibles tablina refuerza la concepción de una estructura itálica y un esquema plenamente romano ya que éste es un elemento claramente itálico y no griego.

La casa 1 es quizás el ejemplo más claro de esta romanización de la Emporion griega debido a que se compone de un atrio y un peristilo. Este peristilo se

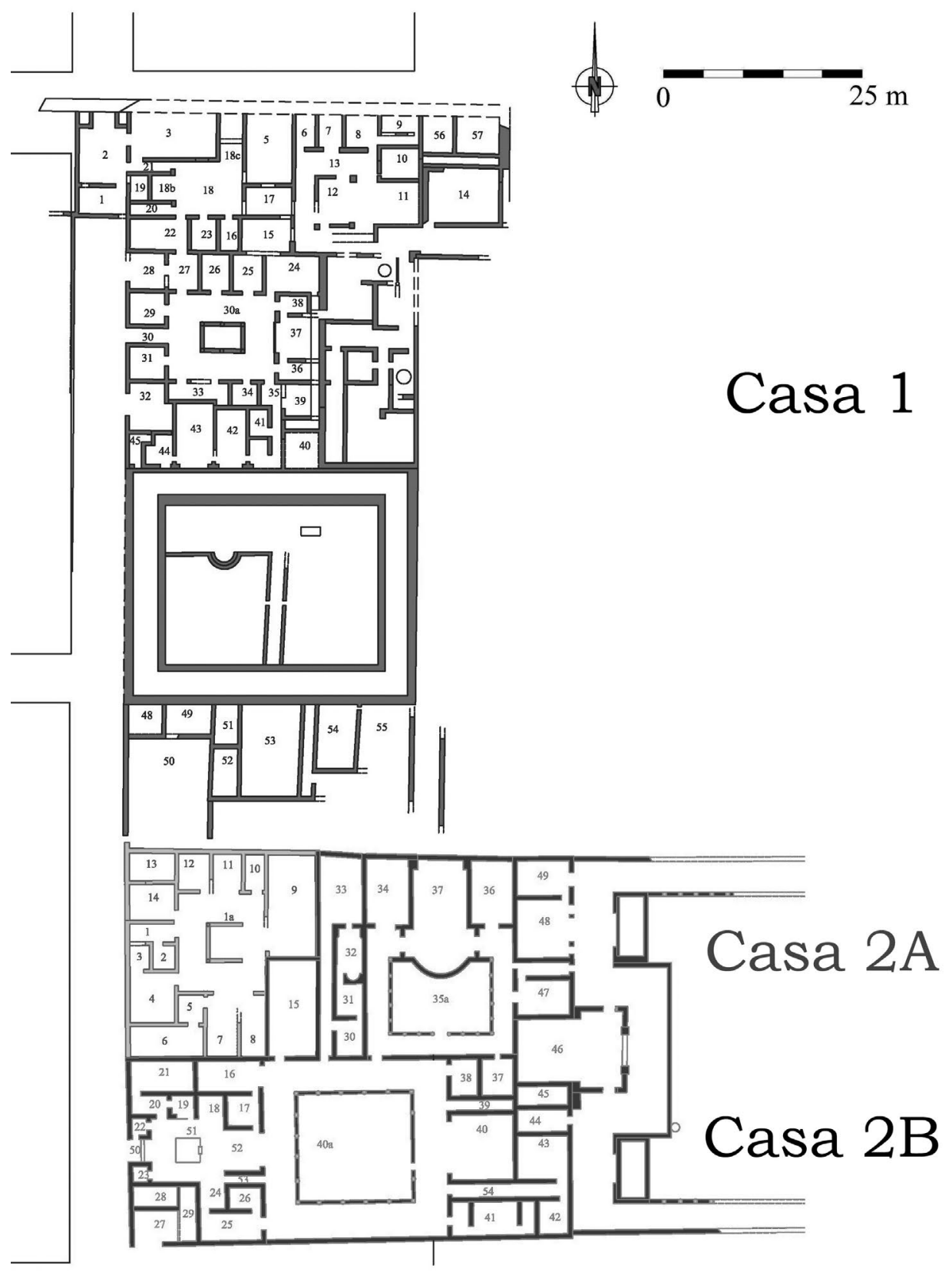

Figura 13: Planta de las casas de la ciudad romana de Ampurias en su máximo desarrollo (Casa 1en rojo y Casa 2B en verde) (base planimétrica: Almagro, 1951). 


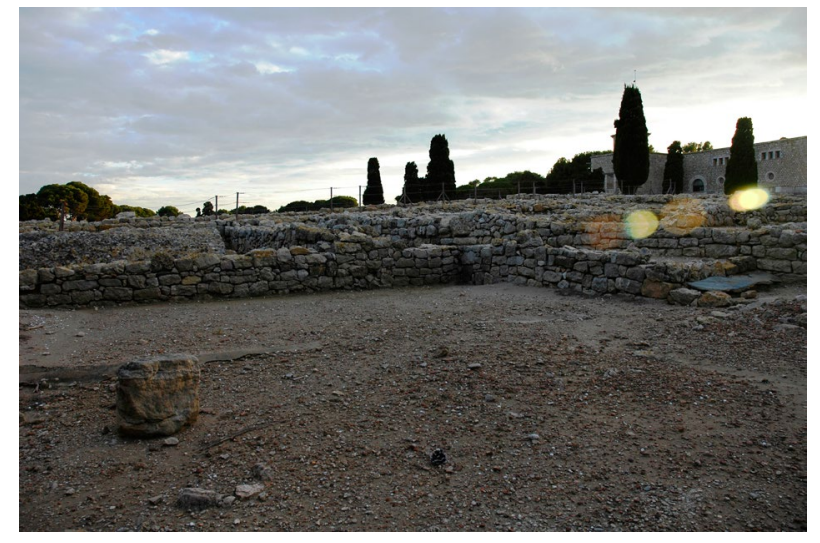

Figura 14: Vista del patio de la casa 80 de la «Neapolis». El estado de erosión de los restos no ha conservado ninguna señal de la existencia de pórticos, pero la amplitud del patio permite suponer su existencia.

construye en una segunda fase, sobrepasando las murallas de la «Neapolis» cuando la ciudad romana y la colonia griega ya son el mismo municipio (Fig. 12). Muy posiblemente esta casa podría haber sido originariamente una casa de atrio, siendo convertida con posterioridad en una casa de atrio y peristilo a imitación de las casas $\mathrm{n}^{\mathrm{o}} 1 \mathrm{y} \mathrm{n}^{\mathrm{o}} 2 \mathrm{~B}$ de la ciudad romana (Santos, 1991; Cortés, 2009, 172-194 y 203-217, 2014, 77-88 y 92-101) (Fig. 13). La similitud de las técnicas utilizadas que se observan en algunos pavimentos de los impluvia de las casas con atrio de la «Neapolis» y la ciudad romana es otro elemento que ayuda a vislumbrar la influencia mutua entre estas dos ciudades ${ }^{3}$. Aparte de todo este influjo romano, el principal exponente de la presencia itálica en la arquitectura doméstica de la colonia griega es la casa de atrio, y esta representa un porcentaje muy reducido dentro del conjunto total de las casas. Así pues, si las estructuras conocidas de la «Neapolis» no se catalogan con las tipologías clásicas griegas ni tampoco el modelo itálico es abundante, entonces se debe definir cuál es el esquema y la influencia que siguen la gran parte de las casas analizadas de la «Neapolis». Algunas reflexiones de Zaccaria nos ofrecen una solución:

«Da quanto dice Vitruvio dunque, nella casa greca si entra direttamente, con la breve mediazione di un corridoio, nel cuore della casa, nel peristilio domestico, sul quale si affacciano tutti gli ambiente, oppure gruppi di ambienti che si raccolgono per aggregazione attorno allo spazio aperto, in una disposizione centripeta. Al contrario nella casa italica c.d. ad atrio la distribuzione delle stanze si dispone in termini di assialità» (Zaccaria, 1995, 291).

3. Los pavimentos de los impluvia de la casa 1 y la casa 34 de la «Neapolis» están hechos de fragmentos de marmorea irregular de la misma factura que el pavimento del impluvium de la casa $\mathrm{n}^{\circ} 1$ de la ciudad romana.

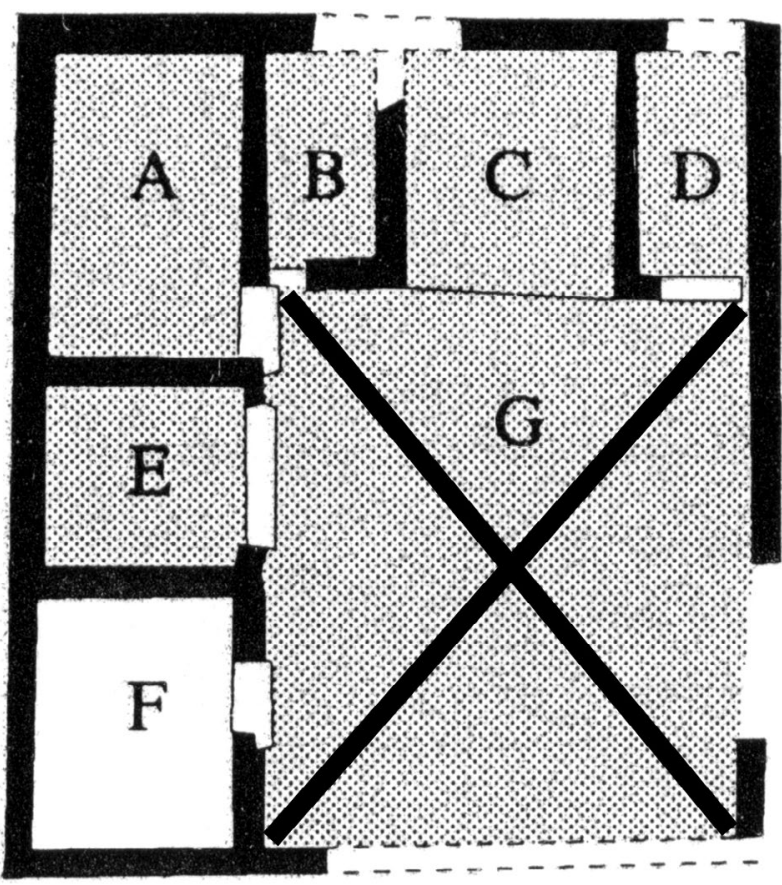

Figura 15: Casa XII (de Sulla) de Glanum (modificado de Bouiron, 1996, 313).

La gran mayoría de las casas de la «Neapolis» se distinguen por ser casas de disposición centrípeta donde mayoritariamente se encuentra un patio en lugar de un peristilo. Esta disposición centrípeta, que como hemos comprobado hasta se puede observar en algunas casas de atrio, se presenta con posterioridad al contacto con los romanos y a la conversión de la «Neapolis» en municipio romano. El caso de Ampurias no es único, como señala Zaccaria (1995, 291-292), también se ha documentado en aquellas ciudades del Mediterráneo Occidental que han mantenido contacto directo con la civilización griega antes que la romana (como por ejemplo Glanum u otras ciudades de la África Septentrional). Muchas de las casas de estas ciudades mantienen una articulación centrípeta después de la colonización romana.

Así pues, las casas de la «Neapolis» no se pueden adscribir a las tipologías clásicas griegas, pero sí que es posible observar de una forma más simple la disposición centrípeta tan común en la casa griega. En la cronología donde se sitúan las casas conservadas de Emporion (a partir de la segunda mitad del siglo II a.C.), se clasifican dentro de una tipología de casa griega heredera de la época helenística, cuando la casa de peristilo está plenamente desarrollada. Pocas casas de la «Neapolis» presentan la tipología de peristilo, pero como se ha descrito, muchas de ellas se desarrollan alrededor de un centro distribuidor, cubierto o descubierto. Aunque no se han conservado, algunos de estos patios podrían haber sido construidos con pórticos como las casas 52 o 80 (Fig. 14). En otras ciudades con influencias griegas además de romanas, también se presentan similitudes en casas articuladas alrededor 

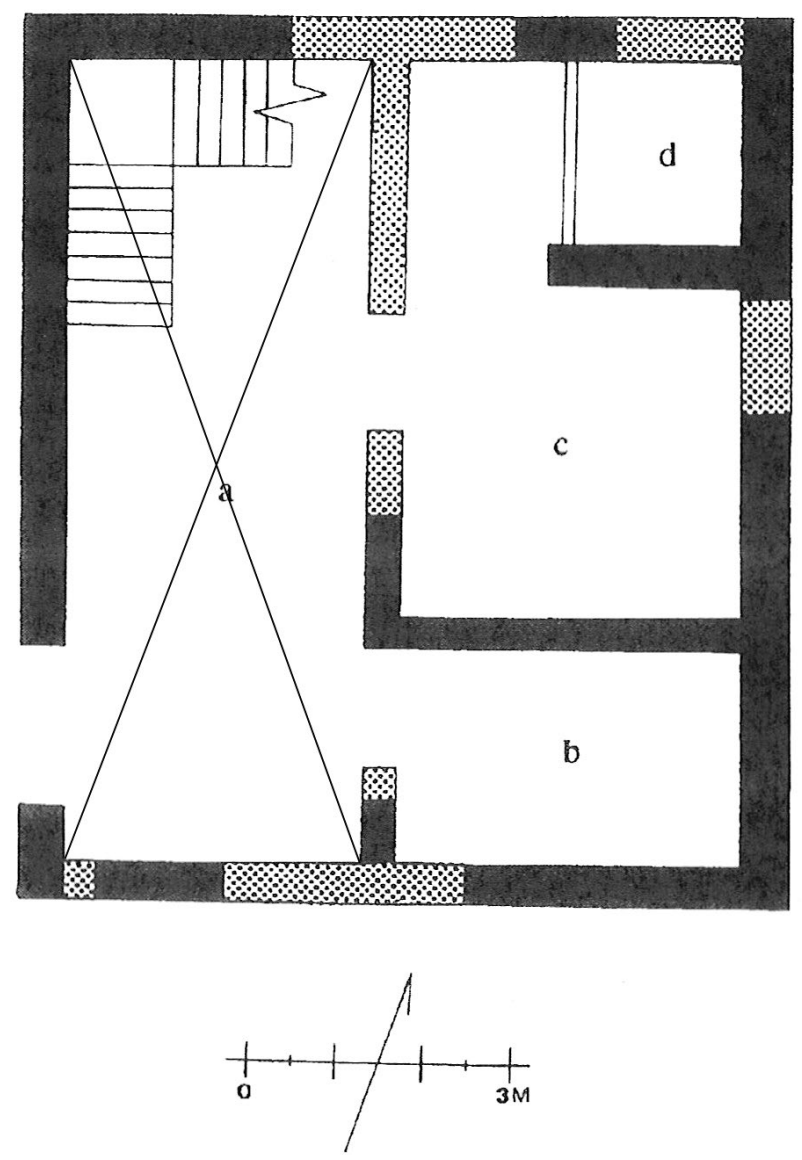

Figura 16: Ejemplo de una casa abierta a un patio de Rhode. Planta de la casa A-II-1 (modificado de Vivó, 1996, 105). de un patio. Un claro ejemplo es la ciudad de Glanum, ubicada en los Alpes. Las casas XII, XVI, XVIII y XIX de la segunda mitad del siglo I a.C. muestran una estructura muy parecida a sus vecinas casas con peristilo, aunque únicamente disponen de un patio simple (Bouiron, 1996, 279-285) en el que se efectúa la entrada directa a la vivienda (Fig. 15). Las casas de la ciudad griega de Ampurias seguirían el mismo esquema a pesar de que en muchos casos sólo presentarían tres o pocas estancias más alrededor del patio. El hecho de encontrar muchas unidades domésticas de dos o tres estancias alrededor de una cuarta que actúa como espacio distribuidor puede ser consecuencia de la densidad de la población, ya que aproximadamente la «Neapolis» era una ciudad de 5 ha para 500 habitantes.

Esta disposición alrededor de un patio se puede observar también en el barrio helenístico de Rhode (Roses, Alto Ampurdán) del s. III a.C. (Fig. 16). Estas casas situadas dentro de un barrio ortogonal no presentan las tipologías clásicas griegas, pero sí se definen como estructuras griegas por sus características. Exceptuando la casa A-II-3 identificada como una posible casa de pastas, las otras viviendas son sencillas con un patio y dos o tres habitaciones multifuncionales con zonas artesanales, pudiéndose definir en ocasiones el oikos (Vivó, 1996, 99-112). Las casas de Ampurias son un poco más tardías y con una influencia itálica que no tienen las del barrio helenístico de Rhode, pero el origen de la estructura griega de las casas de la «Neapolis» dispuestas alrededor de un

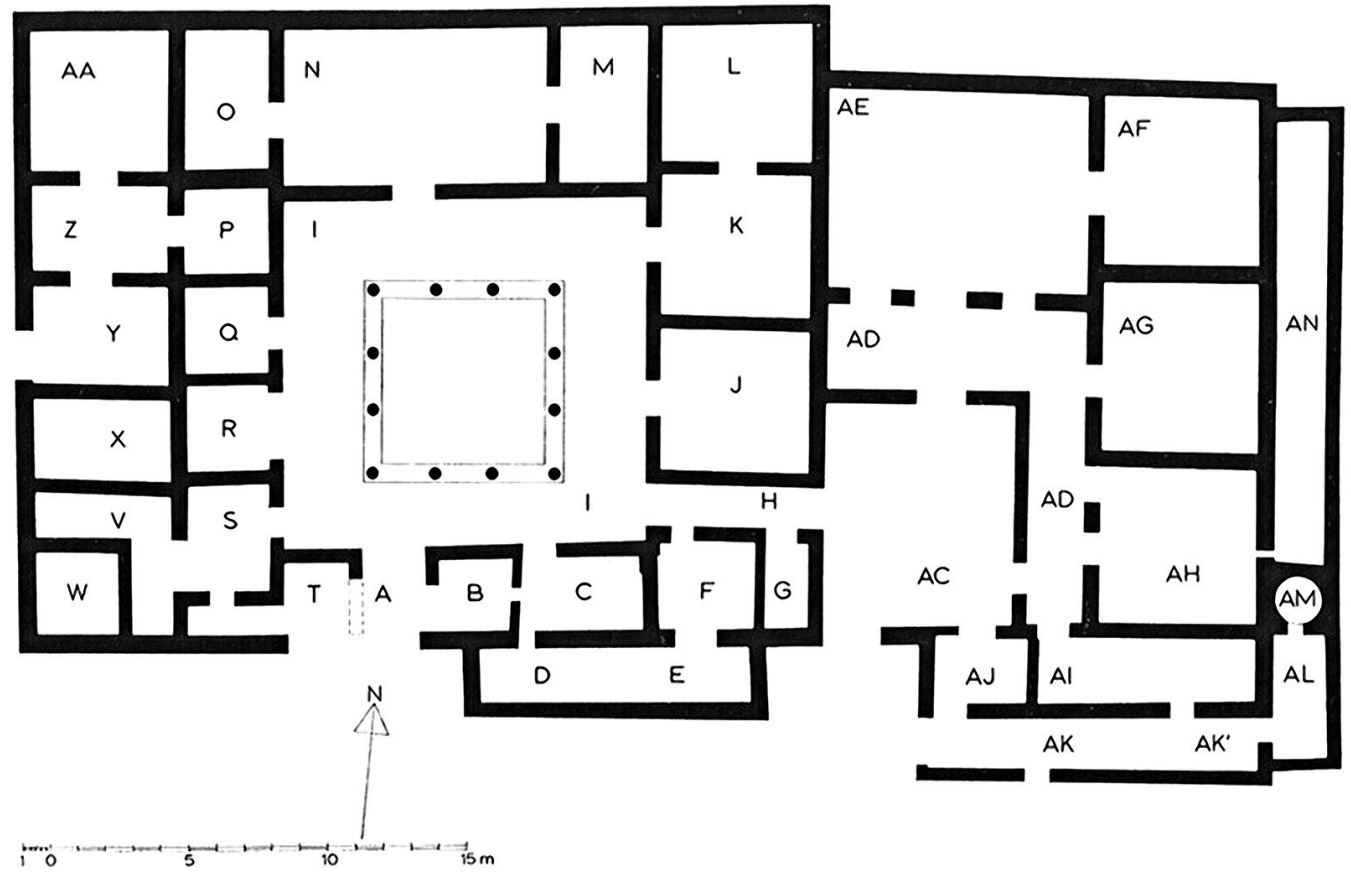

Figura 17: Planta de la Casa de los Comédiens (Bruneau, 1972, 173). 
centro distribuidor cubierto o descubierto serían muy parecidas a éstas.

En la ciudad de Delos se pueden observar otros paralelismos con el enclave griego. En esta localidad es posible vislumbrar otros ejemplos de la influencia del contacto griego además de la posible importación del famoso dios «Esculapio» ${ }^{4}$ (Ruiz de Arbulo y Vivó, 2007, 61-63). Tang (2005, 161) encontró similitudes entre la casa 34 (Fig. 6) y algunas casas de Delos. El esquema tripartito que presentan las habitaciones 8,9 i 10, siendo la habitación 9 la principal y comunicada con las otras dos, es un esquema idéntico a las habitaciones L, K, J de la Casa de los Comédiens (Fig. 17). La casa 34 muestra uno de los pórticos más largos en comparación con el resto, del mismo modo que muchas casas de Delos, como la de los Tritons y la casa de Dyonysos. A pesar de las muchas diferencias que se pueden encontrar entre Delos y Emporion, estas dos ciudades comparten el hecho de haber estado bajo dominio romano a partir del siglo II a.C., aunque Delos mantuvo su personalidad tardoclásica y helenística a pesar de la abundante presencia itálica.

En definitiva, esta disposición alrededor de un espacio central cubierto o descubierto en esquema centrípeto presente después del contacto con los romanos es una de las muestras de esta continuidad de esquemas helenísticos

\section{LA DEFINICIÓN DE LA «CASA DEL PERISTI- LO» DE AMPURIAS}

Como se ha comentado, en la «Neapolis» no se observan las clásicas tipologías de las viviendas griegas, a excepción de la tipología de peristilo. En relación a las casas de esta tipología, se han podido localizar tres ejemplos, las casas 19, 57 y 101 (Fig. 2). Las tres casas muestran diferentes particularidades. El primer ejemplo es la casa 19, cuyo espacio distribuidor es en realidad un patio porticado y que desgraciadamente no se ha conservado la totalidad de su planta. Tal vez la casa 57 es la que presenta un esquema más helenístico, pero con la singularidad de contar con un vestíbulo largo y estrecho al estilo púnico. Pero el ejemplo más conocido es la casa 101, denominada como la Casa del Peristilo de Ampurias.

Este edificio identificado como el modelo de casa de peristilo de la ciudad de Ampurias (Aquilué et alii, 1983, 134-135, Mar y Ruiz de Arbulo, 1993, 388-390) presenta dudas sobre su función como casa privada. $\mathrm{Su}$ estructura corresponde sin duda a la de casa de peristilo, pero sus medidas en comparación con el resto de viviendas de la ciudad son desorbitadas (Fig. 18).

\footnotetext{
4. La atribución de la estatua localizada en Emporion es muy discutida, principalmente entre los dioses Asclepio y Serapis aunque se mantiene la tradición desde su descubrimiento de nombrarlo como el dios romano «Esculapio».
}

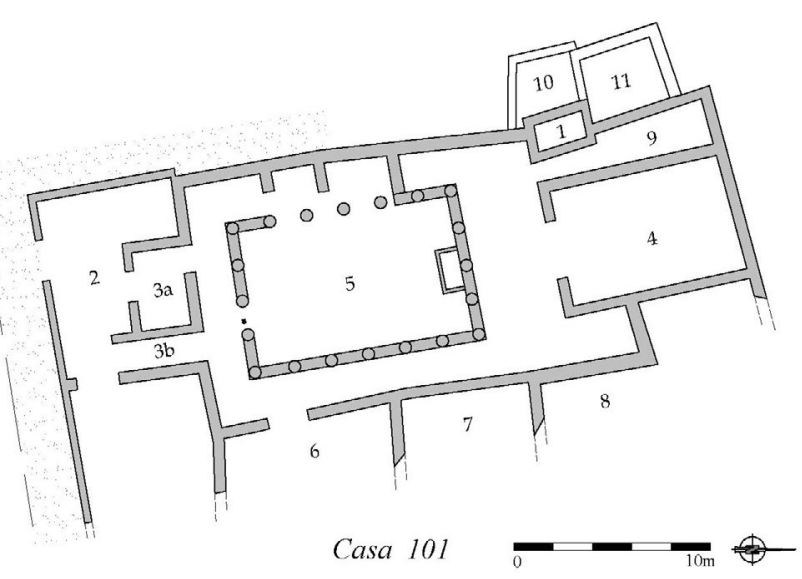

Figura 18: Planta de la casa 101 de la «Neapolis» (base planimétrica: Aquilué et alii,1983, 132).

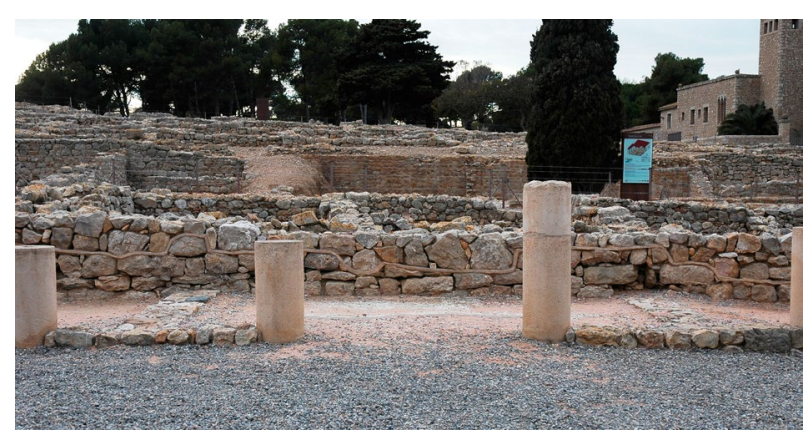

Figura 19: Vista del pórtico occidental de la casa 101 en el que se aprecia los fundamentos de los muros de las exedras que se abren al viridarium.

Este hecho permite interpretar que posiblemente esta casa podría haber sido un edificio «semiprivado» o «semipúblico», posiblemente una sede corporativa. Diferenciar una casa de una sede corporativa es un objetivo difícil, especialmente si no se disponen de restos epigráficos o escultóricos, ya que ambas edificaciones muestran esquemas arquitectónicos muy similares. Uno de los argumentos arquitectónicos a favor de una posible sede corporativa que se desprende del edificio 101 son, en primer y más importante lugar, sus dimensiones. Hay muchas casas de las mismas medidas e incluso mayores como las casas 1 y $2 \mathrm{~B}$ de la ciudad romana, pero el edificio 101 se ubica en un contexto distinto, dentro de la «Neapolis» donde sus proporciones son significativamente mayores que ninguna otra vivienda (Fig. 2, 101). Lo mismo sucede con la sala principal o sala de banquetes (habitación 4) que es la estancia de dimensiones más grandes de toda la ciudad griega (Fig. 18, 4).

Otro elemento importante a destacar es su relación con el ágora de la ciudad. Lamentablemente no es posible apreciar todas las relaciones internas de las habitaciones que limitan con el ágora y sus accesos, ya que podrían mostrar la presencia de tabernae o locales comerciales comunicados entre ellos y sin acceso directo 


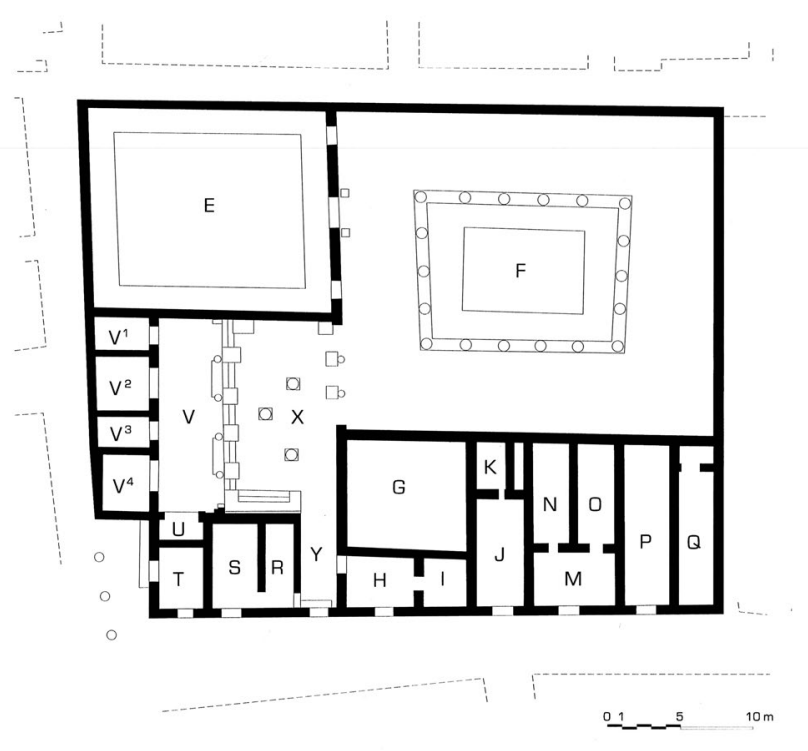

Figura 20: El edificio de los Poseidoniastes de Delos (Bruneau y Ducat, 2005, 229).

a la calle, típico de estos edificios (Carrillo, 1995, 62). También se observa en muchas sedes la presencia de exedras y elementos de culto que en este edificio podrían relacionarse con las exedras construidas en un segundo momento en el peristilo (Fig. 19). Éstas se disponen centradas en el lado occidental del pórtico, rompiendo el ambulacro y abriéndose al jardín. Una ciudad donde se pueden observar edificios corporativos helenísticos parecidos a la casa 101 es Delos con ejemplos como los Poseidoniastes o el establecimiento de los mercaderes de Beirut (Fig. 20). Este edificio construido en la segunda mitad del siglo II a.C. no sólo servía para agrupar a gente de la misma profesión sino también de una misma nacionalidad. La estructura del edificio presenta también un gran espacio de asamblea, un peristilo y una zona de culto, así como una serie de locales y almacenes (Bruneau, 1983, 174177). En conclusión, el edificio 101 podría responder a otras definiciones, pero su identificación como sede corporativa es la más viable según los restos arqueológicos (Cortés, 2014, 74-77).

\section{OTRAS INFLUENCIAS EN LA ARQUITECTU- RA DOMÉSTICA DE LA CIUDAD}

El núcleo griego de Ampurias tuvo contactos con otras culturas además de la griega y la romana, principalmente con íberos, fruto de la convivencia con el asentamiento griego (Sanmartí-Grego, 1993; SanmartíGrego et alii, 1993, 111-112; Sanmartí-Grego, 2000). En la casa ibérica del territorio catalán de finales del siglo II a.C., la existencia de un espacio abierto central es un elemento extraño y difícil de encontrar, pero sí se documenta la presencia de casas levantadas alrededor de un espacio abierto o patio en otros territorios como

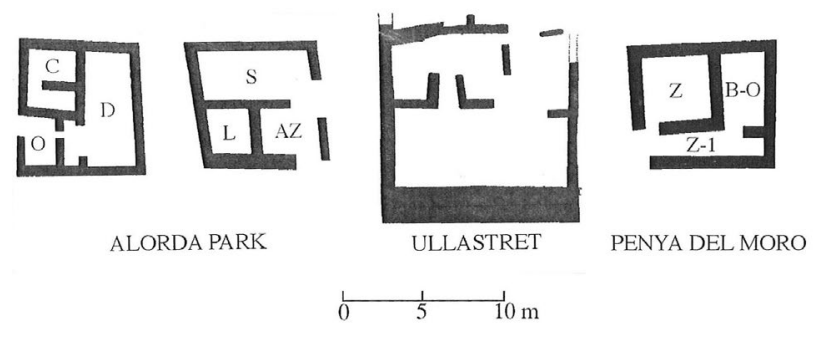

Figura 21: Plantas de las casas ibéricas de Alorda Park, Ullastret y Penya del Moro (Belarte, 1996, 155).

en la Comunidad Valenciana y en Languedoc (Belarte, 1996, 11). A pesar de ello, el estudio de la casa del siglo II a.C. documentada en Lattes, de $290 \mathrm{~m}^{2}$ de superficie y desarrollada alrededor de un patio se considera una influencia helenística o itálica (García, 1994, 167-169). El mismo autor considera que la presencia de un patio asociado a una unidad doméstica es relativamente extraña en la vivienda prerromana meridional de tradición indígena. Asimismo en la «Neapolis» se pueden encontrar paralelos con casas ibéricas en aquellos edificios de pocas habitaciones sin ningún tipo de espacio distribuidor central descubierto o cubierto.

La mayoría de los paralelos que se encuentran en la «Neapolis» corresponden a los que Belarte clasificaba como del tipo B, en sus variantes 1 y 2 (Belarte, 1996, 108; 1997, 155-157) (Fig. 21). Este tipo de casas en la «Neapolis» son las menos documentadas aunque dentro de la tipología de casas con un espacio distribuidor cubierto se podrían encontrar otras similitudes. Estos edificios de la ciudad griega siempre son de planta más rectangular y ortogonal que las casas ibéricas. También es cierto que existen en la «Neapolis» un elevado número de estructuras que no han podido ser identificadas y que podrían hacer aumentar significativamente el conjunto de este tipo de unidad doméstica. Es por ello que el reducido número de ejemplos documentados hace difícil determinar cuál es el grado real de la influencia ibérica en la arquitectura doméstica de Emporion o si por el contrario, su estructura responde a una evolución natural de los edificios aprovechando el espacio restante entre las casas de patio o más rectangulares. Moret (2002, 352-356) reflexionaba sobre la influencia griega en la arquitectura ibérica de $\mathrm{Ca}-$ taluña y Comunidad Valenciana de los siglos V - IV a.C. encontrando que uno de los yacimientos donde más se puede apreciar este componente griego es en el pequeño puerto fortificado de La Picola (Alicante). Moret atribuía la ortogonalidad y la planta regular de las casas al contacto con los griegos aunque sólo encontraba paralelos de los modelos y proporciones en las viviendas de la «Neapolis» emporitana (con fuertes analogías entre La Picola y la Palaiapolis), sin encontrar más paralelos en ningún modelo griego, arcaico o clásico. Por esta falta de paralelos, describió el modelo de la Picola como un modèle inconnu, reconociendo que los conocimientos actuales no permiten establecer las características de las relaciones entre griegos 


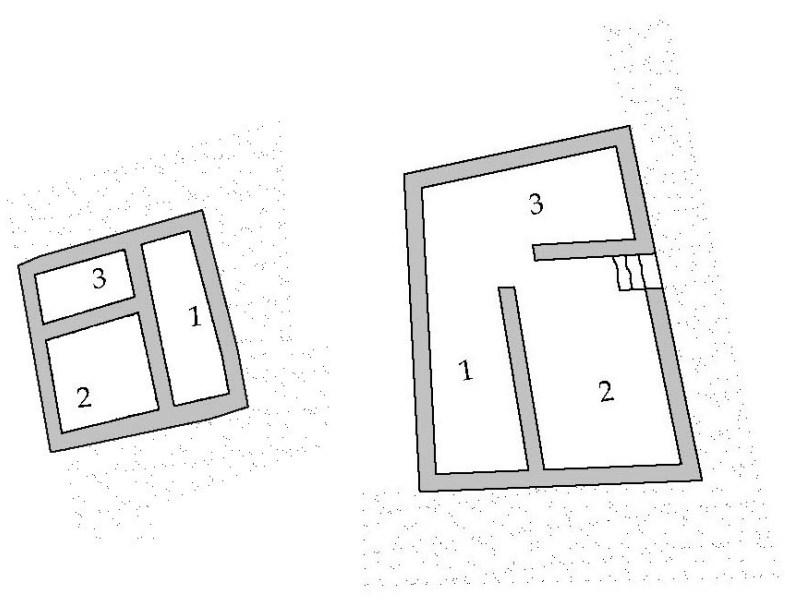

Casa 18

Casa 20

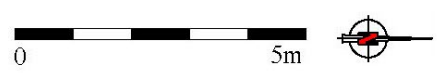

Figura 22: Plantas de las casas 18 y 20 de la «Neapolis» (base planimétrica: Aquilué et alii,1983, 132).

e íberos. Con estas consideraciones es complejo establecer conclusiones entre los intercambios culturales exactos en la arquitectura doméstica de la «Neapolis», pero estas casas que se observan sin espacio distribuidor pueden ser herederas de mutuas influencias a lo largo del tiempo entre griegos e íberos. El resultado son casas con espacios más multifuncionales y con una cierta ortogonalidad (Fig. 22).

La última influencia cultural en la arquitectura doméstica de Emporion que se puede distinguir es la púnica. Esta influencia sólo se percibe en un elemento que se repite en distintas unidades domésticas, las cisternas utilizadas en el asentamiento griego para la recolección de agua. El contacto de Ampurias con el mundo púnico se efectuó a través de las rutas comerciales del sud de la península, sobre todo a partir del siglo IV a.C. (Sanmartí-Grego, 2000), aunque la «Neapolis» ya era un enclave colonial sólido de las rutas del comercio foceo desde finales del siglo VI a.C. (Santos, 2009, 246-248). Un elevado número de cisternas que se localizan en las casas de la «Neapolis» tienen una forma en planta elíptica y paredes verticales. Parece que hay una aceptación general de los estudiosos en que esta tipología es claramente de origen púnico y que las ciudades donde se encuentra esta tipología de cisternas han estado bajo la influencia púnica (Burés, 1998, 60-62). En Cartago a partir del s.III a.C. se observa que mayoritariamente la tipología utilizada para la construcción de las cisternas de las casas es elíptica, igual que en la «Neapolis» (Tang, 2005, 165-166). Este tipo de cisternas se construirían antes de la llegada de los romanos a la ciudad griega, cuando paulatinamente aparecería la cisterna rectangular y con cubierta de bóveda.
Una de las conclusiones más destacadas del estudio sobre las cisternas (Burés, 1998, 102 y 122) es la propuesta cronológica para su construcción. Siguiendo un orden diacrónico, primero se introducirían las cisternas de origen púnico con forma elíptica y cubierta plana. Las casas que con seguridad tuvieron este tipo de cisterna son la casa 9 , la casa $55-56$ y la casa 87 , todas ellas con una disposición centrípeta respecto el espacio distribuidor descubierto. El paso siguiente son las cisternas elípticas con cubierta de bóveda, como la casa 1 de atrio y peristilo (Figs. 10 y 12), las casas de atrio 34 y 85 (Figs. 6 y 7) y la casa 76 de espacio descubierto. Finalmente, las rectangulares con cubierta de bóveda, cisternas comprobadas en la casa 7 de atrio (Figs. 3 y 4) y la taberna de la casa 80 de espacio distribuidor descubierto. La presencia de la cubierta de bóveda, la forma rectangular y la utilización de la piedra calcárea se debe relacionar con la llegada de los romanos, aunque como se observa en las características de las cisternas, es una transformación lenta y evolutiva. Esta información es útil para determinar qué casas se construyeron con seguridad en época romana, como la casa 7 de atrio itálico, en la que tanto su estructura como su cisterna son de influencia itálica. Pero es difícil establecer un paralelismo entre el tipo de casa y una cisterna púnica, ya que la reutilización de las cisternas es un hecho claro en la vida de la «Neapolis» y no se puede establecer con certeza las casas que se construyeron en época anterior a la romana.

En la arquitectura doméstica cartaginesa también se observa una influencia helenística en sus patios, sus pórticos y peristilos (Tang, 2005, 98-101) al igual que la «Neapolis», pero una de las características más propias de la casa púnica son los corredores estrechos y largos que actúan como vestíbulo y que conducen hasta el patio de la casa (Tang, 2005, 98-101). Este tipo de entrada se puede observar en las casas 57 y 80 de Emporion (Fig. 23, B), dos vestíbulos largos que conducen hasta el área distribuidora y descubierta de las respectivas casas. Pero el resto de las estructuras de estas viviendas se distinguen de las parcelas rectangulares y largas de la ciudad cartaginesa (Lancel, 1981, 180) (Fig. 23, A). Además, la casa 80 se relaciona con una cisterna romana y por tanto no tiene más elementos púnicos en su estructura. La casa 57 tiene una cisterna elíptica, pero su cubierta no se ha conservado y no se puede corroborar si era plana al estilo cartaginés o de bóveda. En definitiva, aunque la similitud de estos vestíbulos pueda estar indicando un paralelismo, la cisterna elíptica y su evolución hasta la cisterna rectangular de bóveda es el testimonio más visible del contacto con el mundo púnico.

\section{CONCLUSIÓN}

El estudio de la arquitectura doméstica de Emporion es un camino excelente para poder percibir los intercambios culturales que se dieron antes del cambio de 


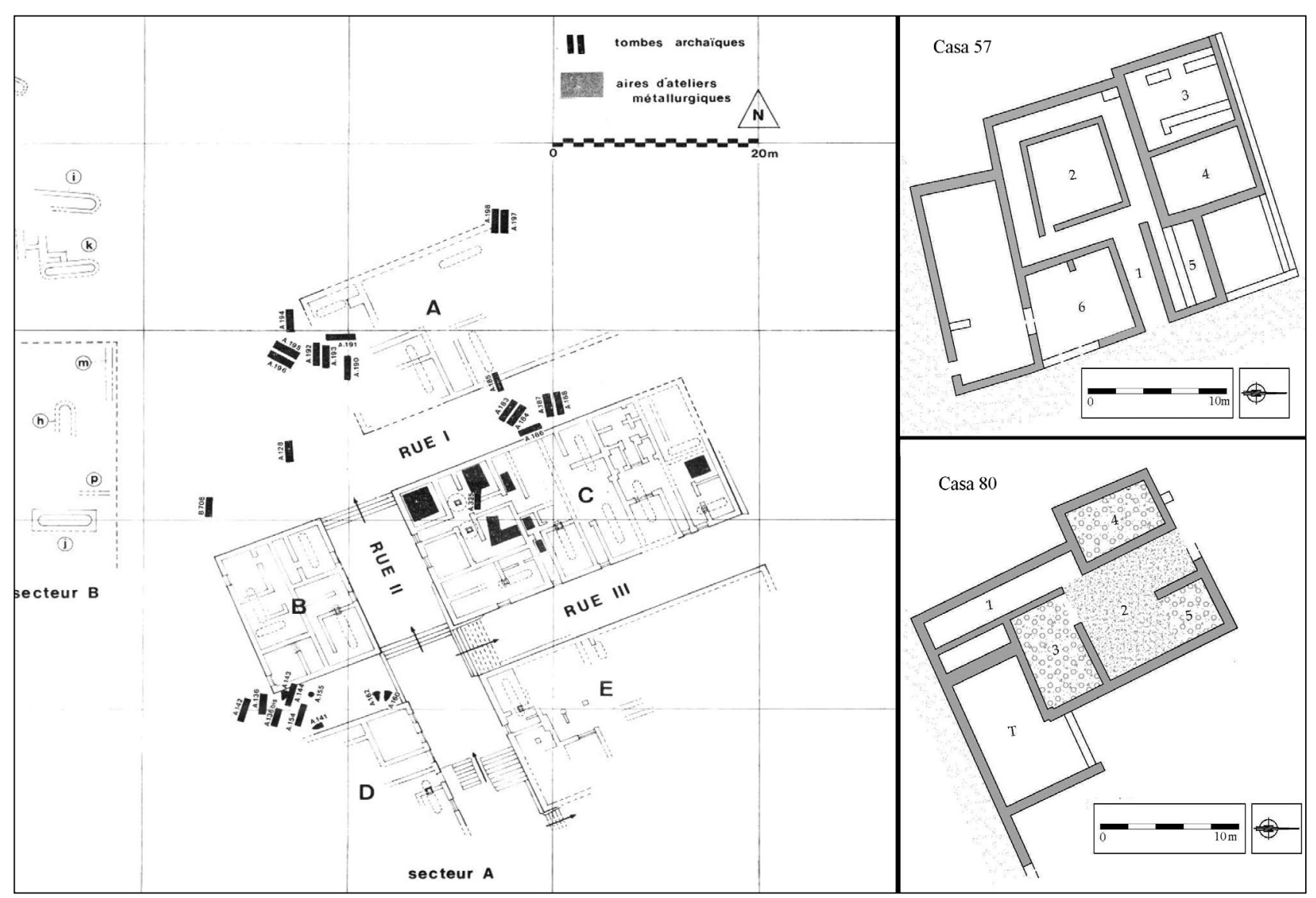

Figura 23: A) Casas del barrio de Aníbal de Cartago (Lancel, 1981, 159). B) Plantas de las casas 57 y 80, vestíbulo nº 1 (base planimétrica: Aquilué et alii, 1983, 132).

era en el Mediterráneo occidental. Influencias, contactos y reciprocidades entre diferentes procesos de construcción y concepciones arquitectónicas que se han materializado en una vivienda particular en el noroeste de la península ibérica.

Recapitulando, una de las características más destacadas de la vivienda de Emporion es la adaptación del esquema itálico dentro de una estructura griega. Casas como la 34 y la 85 , podrían corresponder a la adaptación de nuevos esquemas itálicos con la permanencia de concepciones griegas domésticas. Como bien remarca Gross $(2006,147)$ en las ciudades de Ampurias y Glanum lo importante es la continuidad que se establece en los esquemas propiamente helenísticos e itálicos que permite una actualización de los elementos helenísticos adaptándose a las nuevas tendencias de los territorios occidentales. Por lo tanto, algunas casas de atrio en la «Neapolis» son el producto de la unión de la concepción itálica y griega de la vivienda.

Al mismo tiempo que esta casa híbrida, encontramos casas con un esquema exclusivamente itálico (casa 1 y casa 7), muchas casas de patio herederas de la casa de peristilo helenístico, casas con un ámbito multifuncional de estilo ibérico y casas con elementos arquitectónicos púnicos. Al observar toda esta variedad se pueden establecer diferentes categorías de influencias conviviendo en la misma ciudad. Primero, unas viviendas con una reproducción del esquema itálico republicano, en segundo lugar casas de concepción griega con una voluntad de asimilar elementos itálicos que se diferencian de la tercera categoría de patio con disposición centrípeta. Estas últimas son viviendas que a pesar de tener un contacto fuerte con el mundo itálico mantienen su concepción griega, como la casa 52 y 89 . Las casas con patio de disposición centrípeta representan el porcentaje más elevado de la «Neapolis». Son unidades domésticas particulares que imitan la casa helenística de peristilo, pero que después de la influencia itálica en la ciudad y teniendo en cuenta su determinado espacio urbano, se desarrollan alrededor de un patio. La última categoría de vivienda que se detecta son las casas simples multifuncionales que imitan a sus vecinos autóctonos. Finalmente, se ha de señalar que muchas de los ejemplos de las categorías que cuentan con un espacio distribuidor descubierto, ya sea un atrio, un patio o un peristilo, utilizaban un sistema de almacenaje de agua púnico. En definitiva, una influencia arquitectónica que convergió con todas las concepciones domésticas de la ciudad.

Después de analizar estructuralmente estas casas, separarlas y catalogarlas para intentar profundizar sobre sus diferentes influencias arquitectónicas, se debe tener presente que no deja de ser una disociación 
técnica desde nuestro punto de vista. Como señala Grahame (1998, 175-176) los restos materiales arqueológicos pueden estar indicando una copia de modelos, pero no necesariamente una aculturación de una sociedad concreta sino más bien una adaptación de estilos. Su realidad doméstica debía ser más flexible y continuista, si analizamos por ejemplo algunos detalles decorativos podemos observar parcialmente la complejidad social de sus habitantes y casas en sí mismas eclécticas. La «Neapolis» emporitana no ha conservado gran cantidad de pintura mural, pero sí que ha dejado la huella de diferentes inscripciones en algunos de sus pavimentos de decoración teselada. Las inscripciones griegas son parte del testimonio de los habitantes de esas casas y de las funciones de algunas de sus salas. Por ejemplo el caso de la casa 1, dónde se observan formas de salutación y de buenos augurios en habitaciones de representación (Xaipete $i$ Eytxe ' $Q$ ), que permiten apreciar cómo a pesar de que la casa adquiere patrones itálicos en la estructura, sus habitantes muestran dentro de sus paredes sus costumbres de origen más griego. Esta tradición propia griega aún es más patente en la inscripción del andron de la casa 52 (Hedykoitos) o la sala de representación de la casa 80 (Xaire Agathos Daimon).). Aun así, no es fácil identificar con seguridad a los propietarios de estas estructuras domésticas. En realidad, una de las tareas más difíciles que presentan las ciudades de las distintas provincias es diferenciar la casa de un indígena de clase media-alta romanizado (en este caso un griego en un territorio ibérico) de la casa de un colono itálico que se adapta a nuevas tradiciones autóctonas. Mediante la observación de las casas más acomodadas de la «Neapolis» tal vez podríamos hablar de una clase acomodada de finales de la república e inicios de época imperial, con una fuerte tradición griega pero con importantes contactos con otras culturas mediterráneas e inmersa dentro de un proceso de aculturación itálica, o mejor dicho, de adaptación del estilo romano.

\author{
Dra. Ada Cortés Vicente \\ Bradley Green 8 \\ SO16 Southampton (Reino Unido) \\ adacortesv@gmail.com
}

\section{BIBLIOGRAFÍA}

ALMAGRO, M., 1951: Ampurias; Història de la ciudad, guia de las excavaciones, Barcelona.

AQUILUÉ, X., 2006: «Noves troballes a les excavacions de la ciutat romana d'Empúries», Cota Zero, 21, 17-22.

AQUILUÉ, J., MAR, R. y RUIZ DE ARBULO, J., 1983: «Arquitectura de la Neápolis ampuritana. Espacio y función hacia el cambio de Era», Información Arqueológica, 40, 127-137.

AQUILUÉ, J., MAR, R., NOLLA, J., RUIZ DE ARBULO, J. y SANMARTÍ, E., 1984: El fòrum romà d'Empúries. Excavacions de l'any 1982, Barcelona.
AQUILUÉ, X., CASTANYER, P., SANTOS, S. y TREMOLEDA, J., 2006: «Les termes de la insula 30 (Empúries).», D. VIVÓ (Ed.), Aigua i conjunts termals a les civitates d'Emporiae, Gerunda i Aquae Calidae, 37-44, Girona.

BALIL, A., 1972: Casa y urbanismo en la España Antigua I, Valladolid.

BELARTE, C., 1996: «L'estudi de la casa protohistòrica a Catalunya i àrees adjacents: proposta tipològica i terminològica», Pyrenae, 27, 103-115.

BELARTE, C., 1997: Arquitectura domèstica i estructura social a la Catalunya protohistòrica, Arqueo Mediterrània 1, Barcelona.

BONINI, P., 2006: La casa nella Grecia romana. Forme e funzioni dello spazio privato fra I e VI secolo, Roma.

BOUIRON, M., 1996: «Glanum. Bouches-du-Rhône», La Maison urbaine d'époque romaine en Gaule Narbonnaise et dans les provinces voisines (Actes du colloque d'Avignon, 11-13 novembre 1994), 279-323, Avignon.

BRUNEAU, P., 1972: Exploration archéologique de Délos, 29. Les Mosaïques, Paris.

BRUNEAU, P., 1983: Guide de Délos, $3^{\mathrm{a}}$ edición, Paris.

BRUNEAU, P. y DUCAT, J., 2005: Guide de Délos, Atenas.

BURÉS, L., 1998: Les estructures Hidràuliques a la ciutat antiga: L'exemple d'Empúries, Monografies Empúries 10, Barcelona.

CARRILLO, J. R., 1995: «Las sedes de corporaciones en el mundo romano: un problema de identificación arqueológic», Anales de Arqueologia Cordobesa, 6, 29-77.

CORTÉS, A., 2009: L'arquitectura domèstica de les ciutats romanes de Catalunya. Época tardorepublicana i altimperial, Tesis Doctoral inédita, Universidad Autónoma de Barcelona.

CORTÉS, A., 2011: «L'arquitectura domèstica de la ciutat romana de Barcino», Quaderns d'Arqueologia i Història de la Ciutat de Barcelona, època II, 7, 16-66.

CORTÉS, A., 2014: L'arquitectura domèstica d'època tardorepublicana $i$ altimperial a les ciutats romanes de Catalunya, Serie Studia Archaeologica 1, Barcelona.

CORTÉS, A. y GUITART, J., 2010: «La Arqueología de la casa romana en Cataluña», Bolletino Di Archeologia On Line, Volume Speciale, International Congress of Classical Archaeology. Meetings between cultures in the Ancient Mediterranean (Roma, 2008), 34-49.

GARCIA, D., 1994: «Une maison à cour de plan méditerranéen de la fin de l'Âge du fer à Lattes (l'îlot 9 au IIe s.av.n.è.)», Lattara, 7, 155-169.

GRAHAME, M., 1998: «Material Culture and Roman Identity. The Spatial Layout of Pompeian Houses and the Problem of Ethnicity», Laurence, $R$ and Berry, J. (eds) Cultural Identity in the Roman Empire, 156-178, London.

GROS, P., 2006: L'Architecture romaine, 2.Maisons, palais, villas et tombeaux. Les Manuels d'Art et D'Archéologie Antiques, $2^{\mathrm{a}}$ edición, Paris.

LANCEL, S., 1981: «Fouilles françaises à Carthage. La colline de Byrsa et l'occupation punique, 7e siècle-146 av. J.C. Bilan de sept. années de fouilles», CRAI. Académie des inscriptions et belles-lettres. Comptes rendus des séances de l'année 125, n.2, 156-193. 
LEMAIRE, A., ROBERT, R. y BRAGANTINI, I., 2000: "Le case. Per lo studio delle case romane di Paestum», Paestum. Scavi, studi, ricerche. Bilancio di un decennio, 1988-1998, 157-176, Paestum.

MAR, R. y RUIZ DE ARBULO, J., 1993: Ampurias romana. Història, arquitectura y arqueologia, Sabadell.

MORET, P., 2002: «Maisons phéniciennes, grecques et indigènes: dynamiques croisées en Méditerranée occidentale (de l'Hérault au Segura)», Pallas, 58, 329-356.

PALAUÍ, L. y VIVÓ, D., 1993: «Termes de la 'basílica' d'Empúries», Utilització de l'aigua a les ciutats romanes, Documents d'Arqueologia Clàssica, 0, 103-111.

RUIZ DE ARBULO, J. y VIVÓ, D., 2007: «Els braços del déu. Els peus de la deessa. Serapis i Isis a Empòrion. Barcelona» en T. CARRERAS i M. SÁEZ (Eds.), L'Esculapi. El retorn del déu, 45-65, Barcelona.

SANMARTÍ, E., CASTANYER, P. y TREMOLEDA, J., 1990: «Emporion: Un ejemplo de monumentalización precoz en la Hispania republicana. (Los santuarios helenísticos de su sector meridional)», W. TRILLMICH i P. ZANKER (Eds.), Stadtbild und Ideologie. Die Monumentalisierung hispanischer Städte zwischen Republik und Kaiserzeit, 117-144, Munich.

SANMARTÍ-GREGO, E., 1993: «Els íbers a Emporion (Segles VI-VIII a.C.)», Laietania, 8, 87-101.

SANMARTÍ-GREGO, E., 2000: «Empòrion: una ciutat grega a Ibèria», P. CABRERA i C. SÁNCHEZ (Eds.), Els
Grecs a Ibèria. Seguint les passes d'Heracles, 109-118, Barcelona.

SANMARTÍ-GREGO, E., CASTAÑER, P. y TREMOLEDA, J., 1993: «Nuevos datos sobre la historia y la topografía de las murallas de Emporion», Madrider Mitteilungen, 33, $100-112$.

SANTOS, M., 1991: «Distribución y evolución de la vivenda urbana tardorrepublicana y altoimperial en Ampurias», La Casa Urbana Hispanorromana. Ponencias y comunicaciones, 19-34, Zaragoza.

SANTOS, M., 2008: « L'arqueologia grega a Empúries. Un discurs en construcción», 100 anys d'excavacions arqueològiques a Empúries. Hipòtesis i certeses, Annals de l'Institut d'Estudis Empordanesos, 39, 40-79, Figueres.

SANTOS, M., 2009: «Emporion, la nave de Cala Sant Vicenç y el comercio foceo en occidente a finales del siglo $\mathrm{VI}$ aC», Traffici, commerci e vie di distribuzione nel Mediterraneo, tra protostoria e V secolo a.C. (Gela, 27-29 maggio 2009), 243-254, Gela.

TANG, B., 2005: Delos, Carthage, Ampurias. The housing of three Mediterranean Trading Centres, Roma.

VIVÓ, D., 1996: «Rhode: arquitectura i urbanisme del barri hel-lenístic», Revista d'Arqueologia de Ponent, 6: 81-117.

ZACCARIA, A., 1995: Spazio privato e spacio pubblico nella città romana, Roma.

Recepción: 25-09-2013

Aceptación: 27-01-2014 